\title{
A variação lexical para peças do vestuário íntimo em um recorte do Projeto ALiB
}

\section{The lexical variation for underclothing in an extract from the ALiB Project}

\author{
Maria Bethânia Gomes Paes ${ }^{1}$ \\ Marcela Moura Torres Paim²
}

Resumo: Este artigo insere-se na perspectiva de investigação lexical e propõe o levantamento das denominações para vestuário íntimo usadas por falantes de cinco pontos distribuídos entre os Estados de Alagoas e Sergipe. Realizou-se análise da variação semântico-lexical constantes no corpus do Projeto Atlas Linguístico do Brasil (ALiB) nos referidos pontos do Nordeste do Brasil. A metodologia consistiu na leitura de textos teóricos referentes ao tema; seleção do corpus, constituído de inquéritos de pontos situados no interior dos referidos estados, do banco de dados do Projeto ALiB; análise dos dados, verificando-se relações entre o uso das variantes lexicais e fatores sociais. Foram considerados inquéritos de informantes dos grupos etários I (18-30 anos) e II (50-65 anos) do Questionário Semântico Lexical do ALiB, campo semântico vestuário e acessórios (itens calcinha e cueca) para a análise da seleção lexical realizada por falantes de cidades do Nordeste brasileiro. Pretende-se, portanto: (i) registrar as denominações para calcinha e cueca nos pontos supracitados; (ii) analisar as lexias e suas relações com fatores sociais relacionados aos informantes; (iii) confeccionar cartas linguísticas que retratem diatopicamente as variantes lexicais no Brasil. A análise do corpus possibilitou o registro da diversidade lexical do português falado no Brasil, considerando-se princípios da Dialetologia Pluridimensional.

Palavras-chave: Dialetologia; Variação; Léxico.

Abstract: This article shows a lexical research and proposes the survey of the denominations for underclothing used by speakers living in five points located in he States of Alagoas and Sergipe. It was done an analysis of the semantic-lexical variation in the corpus of the Brazilian Linguistic Atlas Project (ALiB Project) considering the data of these points situated in the Northeast of Brazil. The methodology used consisted of the reading of theoretical texts related to the proposed theme; selection of the corpus, consisting of surveys of inquires relationed to the points located in the towns on the interior of those states, wich are parts of the ALiB Project database; analysis of this corpus in order to verify the relations of use of the lexical variants with social factors. The informants' inquiries of age groups I (18-30 years) and II (50-65 years) of the Lexical Semantic Questionnaire of the ALiB Project of the semantic field clothing and accessories (items underwear and panties) were considered in order to analyze the lexical selection performed by informants from different age groups from different Brazilian Northeast cities. They are intended, therefore, in the corpus in question: (i) to register the denominations for the lexical items underwear and panties in the aforementioned points; (ii) analyze the documented items and their relationships with social factors related to the informants; (iii) to make linguistic charts that depict diatopically the lexical variants of underwear and panties in Brazil. The analysis of the corpus allowed the registration of the lexical diversity of Portuguese spoken in Brazil, considering the principles of Multidimensional Dialectology.

Keywords: Underwear. Panties. Lexical Variants.

${ }^{1}$ Doutoranda em Língua e Cultura- UFBA- campus Salvador. Email: bethapaes@yahoo.com.br.

${ }_{2}^{2}$ Professora Permanente do Programa de Pós-Graduação em Língua e Cultura da Universidade Federal da Bahia- UFBA. E-mail: marcelamtpaim@yahoo.com.br 


\section{Introdução}

O termo léxico poder ser compreendido como "um depósito de elementos de designação, o qual fornece unidades básicas para a construção dos enunciados", segundo Basílio (2017, p. 9). No entanto, ainda conforme a autora, não se trata apenas de um conjunto definido de palavras, mas de um campo marcado pela dinamicidade característica da língua e, portanto, de seus usuários, os quais estão imersos em comunidades sujeitas às mais diversas interferências advindas das transformações sociais, culturais e econômicas em diferentes espaços e tempos. E este caráter dinâmico da língua faz do léxico uma importante fonte de estudos para a documentação da variação nas diversas línguas existentes no mundo.

O presente trabalho insere-se na perspectiva dos estudos semântico-lexicais considerados no Projeto Atlas Linguístico do Brasil (ALiB) e propõe analisar as designações referentes aos itens lexicais cueca e calcinha no repertório linguístico de informantes da faixa etária I (18-30 anos) e da faixa etária II (50- 60 anos) do Questionário Semântico Lexical do Projeto ALiB, no campo semântico vestuário e acessórios, a fim de averiguar a seleção lexical dos informantes das duas faixas etárias supracitadas em cinco pontos distribuídos nos estados de Alagoas e Sergipe.

Este estudo justifica-se por tomar o léxico como ponto de partida para compreender, investigar, descrever e explicar a percepção que determinado grupo tem do mundo que o circunda, o que também, de acordo com Paim (2012), permite o conhecimento e a manutenção de parte da memória sócio-histórica e linguístico cultural da comunidade, além do registro e sistematização da diversidade lexical e geolinguística do português falado no Brasil, confirmando, mais uma vez sua relevância para os estudos (socio) linguísticos.

\section{Pressupostos teóricos}

A pesquisa ora apresentada inscreve-se na perspectiva teórico-metodológica da Dialetologia Pluridimensional. Trata-se de um ramo da Linguística que consiste em observar a língua e suas variantes quanto a sua distribuição espacial, utilizando como método a Geolinguística Contemporânea que, além de levar em conta a procedência geográfica dos indivíduos, também considera fatores como o sexo, a idade e o nível escolaridade. Assim, conforme Cardoso (2010, p. 15), o espaço geográfico é marcado pelas singularidades de seu povo também por meio da variedade linguística observada de uma região para outra, o que evidencia aspectos ligados à diversidade cultural, à formação territorial e à própria base linguística e prováveis interferências de outras línguas naquele espaço ao longo de sua história.

Ainda de acordo com Cardoso (2010, p. 25), pode-se pensar que Sociolinguística e Dialetologia têm o mesmo foco, uma vez que a Dialetologia, por tomar a língua como objeto de estudo, não desprezar fatores extralinguísticos, inerentes aos falantes e com importantes implicações na fala, a fim de identificar áreas geograficamente definidas a partir do ponto de vista dialetal, e, ainda, por considerarem a variação 
linguística no cerne de seus pressupostos. No entanto, há diferenças entre esses dois ramos de estudos da língua no que diz respeito à forma de tratar os fenômenos e de abordar os fatos linguísticos, como destaca a autora a seguir:

A dialetologia, nada obstante considerar fatores sociais como elementos relevantes na coleta e tratamento dos dados, tem como base da sua descrição a localização espacial dos fatos considerados, configurando-se, dessa forma, como eminentemente diatópica. A sociolinguística, ainda que estabeleça a intercomparação entre dados diferenciados do ponto de vista espacial, centra-se na correlação entre os fatos linguísticos e os fatores sociais, priorizando, dessa forma, as relações sociolinguísticas. (CARDOSO, 2010, p. 26)

Entretanto, os objetivos desses dois ramos dos estudos linguísticos são perfeitamente delineáveis, conforme destacado por Corvalan (1988, p. 8 apud CARDOSO, 2010, p. 26):

\begin{abstract}
Sociolinguística e dialetologia se tem considerado até certo ponto sinônimas uma vez que ambas as disciplinas estudam língua falada, o uso linguístico e estabelecem as relações que existem entre certos traços linguísticos e certos grupos de indivíduos. Assim como a sociolinguística, a dialetologia reconheceu desde cedo a existência da heterogeneidade linguística. (CORVALAN, 1988, p. 8 apud CARDOSO, 2010, p. 26)
\end{abstract}

Chambers e Trudgill (1994, p.19) destacam o dialeto como foco de estudo da Dialetologia, suscitando uma discussão acerca da dificuldade em se definir o termo, sobretudo, no que concerne à diferenciação e ao limite a ser estabelecido entre língua e dialeto. Dessa forma, afirmam ser melhor a adoção do termo variedade em lugar de língua, de forma a contemplar qualquer classe particular de língua que se deseja considerar. $\mathrm{O}$ dialeto, portanto, corresponderia às variedades que se diferem considerando o prisma gramatical, fonológico e lexical.

\title{
O ALiB e os estudos do léxico
}

Cardoso (2010, p. 168) aponta a necessidade do conhecimento sistemático e geral da realidade linguística brasileira, de modo a reafirmar o caráter pluricultural do Brasil. Daí a urgência de uma descrição profunda da realidade linguística brasileira, uma vez que, ainda conforme a autora, apesar de ter-se estudos preliminares, a exemplo daquele desenvolvido por Nascentes (1953), fundamentado na realização das vogais médias pretônicas e na entonação, ainda é preocupante a ausência de dados linguísticos que auxiliem na delimitação de áreas dialetais do Brasil. E o ALiB constitui-se, também por iniciativa da saudosa linguista, a fim de registrar as diversas variedades linguísticas observadas no território brasileiro.

O Projeto Atlas Linguístico do Brasil (ALiB) é uma iniciativa de caráter nacional, com vistas a descrever a realidade do português falado em território nacional, de modo a sistematizar os comportamentos observados no Brasil em um atlas geral. Considerando a perspectiva da Dialetologia Pluridimensional, sinaliza as diferenças diatópicas, diastráticas, diagenéricas e diageracionais, tomando-se os diferentes níveis de análise da língua. O Projeto ALiB tem como meta o mapeamento da realidade linguística do Brasil partindo dos dados coletados in loco em 250 pontos, que representam todas as regiões brasileiras, junto a 1.100 informantes dos dois sexos, igualmente distribuídos em duas faixas 
etárias - 18 a 30 anos e 50 a 60 anos. Em 25 capitais do país (Palmas, e todo o estado de Tocantins, e Brasília, Distrito Federal foram excluídas da rede de pontos por questões metodológicas por conta de serem localidades recém-criadas), foram entrevistados indivíduos com os níveis de escolaridade fundamental e universitário, sendo que os demais pontos da rede contribuíram com os dados de informantes do nível fundamental. Trata-se, pois, de uma importante fonte de pesquisa e compreensão dos fenômenos linguísticos e sociais que atuam na formação/transformação do Português Brasileiro, explicitando o caráter heterogêneo e dinâmico inerente às línguas vivas presentes no mundo.

Entende-se que partir do estudo do léxico dos falantes brasileiros é extremamente relevante para entender os fenômenos intra e extralinguísticos que acometem a língua, em busca de determinar isoglossas no território do país. Justifica-se tal posicionamento considerando-se o que afirmam Oliveira e Isquerdo (1998, p.7), para as quais as realizações lexicais dos indivíduos podem expressar sua visão de mundo, suas crenças e ideologias, seus valores e a norma linguística aprendida através das práticas socioculturais presentes em seu grupo social, que, geralmente, mantêm entre si uma identidade linguística. Nesse sentido, Paim (2012, p. 268) verificou que "[...] a identidade social de faixa etária se constrói pela revelação de que no passado as próprias informantes utilizavam um item lexical diferente, caracterizado por porta-seio e corpinho, vinculado a uma fase anterior de suas vidas" ao estudar as designações para peça do vestuário que serve para segurar os seios na fala de informantes das capitais do Brasil. A variação diageracional, configura-se, portanto, como ponto interessante a ser considerado nas pesquisas que tomam o léxico como objeto de estudo, pois revela a seleção lexical dos informantes segundo a faixa etária a qual pertencem.

Ribeiro (2009, p. 239-261), em um estudo sobre as denominações para diversos brinquedos e brincadeiras infantis considerando os dados do ALiB recolhidos no Nordeste brasileiro, observou que as variáveis gênero e faixa etária não figuraram como relevantes para a determinação da forma lexical mobilizada pelos informantes como resposta às perguntas para verificar designações para os doze jogos e diversões infantis considerados no referido trabalho. A linguista conclui que o grau de escolarização foi a variável mais relevante para a determinação da variante lexical utilizada como primeira resposta pelos informantes às perguntas da área semântica jogos e brincadeiras.

Estudos da variação lexical no PB feitos por Paim (2011, 2012), atendo-se ao campo semântico vestuário e acessórios, observados no corpus do ALiB, especificamente das capitais do Brasil, apontaram a presença de expressões temporais associadas ao uso de variantes linguísticas, algumas delas concentrando-se nos dados de indivíduos de uma determinada faixa etária.

Esta pesquisa concentra-se na tarefa de fazer o mapeamento para as denominações relacionadas à cueca e à calcinha, contemplando também os pontos concentrados no interior dos estados brasileiros (por ora aqueles situados nos estados de Alagoas e Sergipe), a fim de dar continuidade ao estudo de Paim $(2011,2012)$ e confeccionar cartas linguísticas que retratem as variantes lexicais desses referidos itens lexicais no Brasil.

\section{Metodologia}


Para a constituição do corpus, foram considerados dados provenientes das respostas às questões de número 189 (Qual a roupa que o homem usa debaixo da calça?) e 190 (Qual a roupa que a mulher usa debaixo da saia?) do Questionário Semântico Lexical - QSL, que constam no Questionário do ALiB 2001 (COMITÊ NACIONAL DO PROJETO ALIB, 2001).

Os participantes da pesquisa são organizados por faixa etária, sexo e escolaridade, variáveis sociais controladas pelo ALiB da seguinte maneira:

a. faixa etária: faixa 1 - informantes com idade entre 18 e 30 anos; faixa 2- informantes com idade entre 50 e 65 anos;

b. sexo: homens e mulheres;

c. escolaridade: indivíduos de nível universitário (somente para as capitais) e indivíduos de nível fundamental incompleto.

A amostra constituída para esta pesquisa considera os dados obtidos com a aplicação dos inquéritos linguísticos a 20 informantes, quatro por localidade, distribuídos de acordo com a metodologia do Projeto ALiB: (i) 10 informantes por sexo: masculino (M) e feminino (F); (ii) 36 informantes por faixa etária: faixa 1, entre 18 e 30 anos, e faixa etária 2, entre 50 e 65 anos. Como os dados foram recolhidos de inquéritos aplicados a informantes residentes no interior do Brasil, todos os sujeitos da pesquisa possuem o nível de escolaridade fundamental incompleto. Foram analisados os registros das gravações de 20 informantes distribuídos em pontos do ALiB nos Estados de Alagoas e Sergipe, a saber: em Alagoas, serão examinados os inquéritos referentes aos pontos 74- União dos Palmares, 75- Santana do Ipanema e 76- Arapiraca; em Sergipe, serão examinados os inquéritos dos pontos 78- Propriá e 80- Estância.

A pesquisa adotou o método qualitativo e quantitativo, uma vez que, além do número de lexias encontradas, considerou o falante em suas relações sociais, verificando-se, assim, a variação e a constituição lexical, segundo as variáveis diassexual, diatópica e diageracional. O estudo, portanto, considera os pressupostos teórico-metodológicos da Dialetologia Pluridimensional, aliado ao método de análise das variáveis estudadas pela Sociolinguística.

\section{Análise dos dados}

Nesta seção, serão apresentadas inicialmente as designações para vestuário íntimo nos dicionários da Língua Portuguesa e, posteriormente, faz-se a análise dos dados observados neste artigo.

As designações para vestuário íntimo nos dicionários da Língua Portuguesa.

Os Quadros 1 e 2 indicam, respectivamente, quais as designações encontradas para roupa que 0 homem usa debaixo da calça e para roupa que a mulher usa debaixo da da saia nos pontos do ALiB situados nos Estados de Alagoas e Sergipe estão registradas nos referidos dicionários da Língua Portuguesa.

Quadro 1: Registro das variantes de cueca nos Dicionários de Ferreira (2004) e Houassis (2009).

\begin{tabular}{|l|l|l}
\hline Roupa que o homem & Lexia em Ferreira & Lexia em Houaiss
\end{tabular}




\begin{tabular}{|l|l|l|}
\hline usa debaixo da calça & \multicolumn{1}{|c|}{$(2004)$} & \multicolumn{1}{|c|}{$(2009)$} \\
\hline Cueca & Dicionarizada. & Dicionarizada. \\
\hline Zorba & Não dicionarizada. & Não dicionarizada. \\
\hline Sunga & Dicionarizada. & Dicionarizada. \\
\hline Samba canção & Dicionarizada. & Dicionarizada. \\
\hline Calção & Dicionarizada. & Dicionarizada. \\
\hline Ceroula Fonte: elaborado pelas autoras. & Dicionarizada. \\
\hline
\end{tabular}

Quadro 2: Registro das variantes de calcinha nos Dicionários de Ferreira (2004) e Houassis (2009)
\begin{tabular}{|l|l|l|}
\hline $\begin{array}{l}\text { Roupa que a mulher } \\
\text { usa debaixo da saia }\end{array}$ & \multicolumn{1}{|c|}{$\begin{array}{c}\text { Lexia em Ferreira } \\
(2004)\end{array}$} & $\begin{array}{c}\text { Lexia em Houassis } \\
(2009)\end{array}$ \\
\hline Calcinha & Dicionarizada. & Dicionarizada. \\
\hline Saiote & Dicionarizada. & Dicionarizada. \\
\hline Biquíni & Dicionarizada. & Dicionarizada. \\
\hline Tanga & Dicionarizada. & Dicionarizada. \\
\hline Fio dental & Dicionarizada. & Dicionarizada. \\
\hline Calçola/ calçolão & Dicionarizada. & Dicionarizada. \\
\hline
\end{tabular}

Fonte: elaborado pelas autoras.

Observa-se nos Quadros 1 e 2 que zorba foi a única lexia não dicionarizada, mas que foi utilizada por informantes situados em pontos de Alagoas e Sergipe. Trata-se de uma ocorrência que remete à figura de linguagem metonímia, que consiste no fato de uma palavra ser substituída por outra por proximidade de sentido. Nesse caso, zorba é uma marca conhecida que se dedica à produção e comercialização de roupas íntimas masculinas.

\section{Os dados e as dimensões diatópica, diassexual e diageracional}

Análise das designações para roupa que o homem usa debaixo da calça.

O Quadro 3 apresenta quantitativamente o uso das variantes pelos informantes dos pontos do ALiB situados no Estado de Alagoas para a pergunta: Qual a roupa que o homem usa debaixo da calça? Foram registrados os itens lexicais cueca, zorba, sunga, samba canção, calção e ceroula na referida área.

Quadro 3: Designações para roupa que o homem usa debaixo da calça em Alagoas.

\begin{tabular}{|l|c|c|c|}
\hline & União dos Palmares & Santana do Ipanema & Arapiraca \\
\hline
\end{tabular}




\begin{tabular}{|l|c|c|c|}
\hline Cueca & 4 ocorrências & 4 ocorrências & 4 ocorrências \\
\hline Zorba & 2 ocorrências & 1 ocorrência & ---- \\
\hline Sunga & ---- & 1 ocorrência & 1 ocorrência \\
\hline Samba canção & ---- & 1 ocorrência & --- \\
\hline Calção & ---- & ---- & 1 ocorrência \\
\hline Ceroula & ---- & ---- & --- \\
\hline
\end{tabular}

Fonte: elaborado pelas autoras.

Os dados demonstram que a variante cueca é a mais recorrente entre os informantes dos pontos do ALiB situados em Alagoas, sendo observada na fala dos 12 sujeitos considerados no Estado, como resposta à pergunta 189 do QSL.

A variante zorba é a segunda lexia mais utilizada em resposta à pergunta 189 do ALiB, figurando na fala de 3 dos 12 informantes considerados em Alagoas. No ponto de Arapiraca, não foi registrada tal variante, sendo observada em União dos Palmares (dois informantes) e Santana do Ipanema Palmares (um informante). Quanto à dimensão diassexual, o item lexical zorba foi observado apenas nos dados de mulheres de ambas as faixas etárias de União dos Palmares e Santana do Ipanema, o que não correu nos dados de mulheres de Arapiraca, como apresentado no Quadro 4.

A lexia sunga é a terceira variante mais utilizada em resposta à pergunta 189 do ALiB (2 ocorrências), constando nos registros de informantes de Santana do Ipanema e de Arapiraca, com uma ocorrência em cada ponto. As duas ocorrências encontradas estão na fala da informante mulher, faixa etária 1, em Santana do Ipanema e na fala do informante homem, faixa etária 2, em Arapiraca. Portanto, sunga não consta nos dados de homens e mulheres, de ambas as faixas etárias, de União dos Palmares.

Samba canção ocorreu apenas uma vez no recorte considerado, nos dados de homem, faixa etária 1, natural de Santana do Ipanema.

Calção ocorreu apenas uma vez no recorte considerado, nos dados da mulher de faixa etária 1 , natural de Arapiraca.

Quadro 4: Distribuição diassexual/ diageracional das variantes para roupa que o homem usa debaixo da calça em

\begin{tabular}{|l|c|c|c|c|}
\hline \multirow{2}{*}{ Localidades } & \multicolumn{2}{|c|}{ Homem } & \multicolumn{2}{c|}{ Mulher } \\
\cline { 2 - 5 } & faixa etária 1 & faixa etária 2 & faixa etária 1 & faixa etária 2 \\
\hline $\begin{array}{l}\text { União dos } \\
\text { Palmares }\end{array}$ & cueca & cueca & cueca, zorba \\
\hline $\begin{array}{l}\text { Santana } \\
\text { Ipanema }\end{array}$ & $\begin{array}{c}\text { cueca, samba } \\
\text { canção }\end{array}$ & cueca & cueca, sunga & corba \\
\hline Arapiraca & cueca & cueca, sunga & cueca, calção & Cueca \\
\hline
\end{tabular}

Fonte: elaborado pelas autoras. 
Apresenta-se, na Figura 01, a carta linguística formulada com base na distribuição diatópica das lexias referentes às denominações para roupa que o homem usa debaixo da calça em Alagoas.

Figura 01. Denominações para roupa que o homem usa debaixo da calça em Alagoas

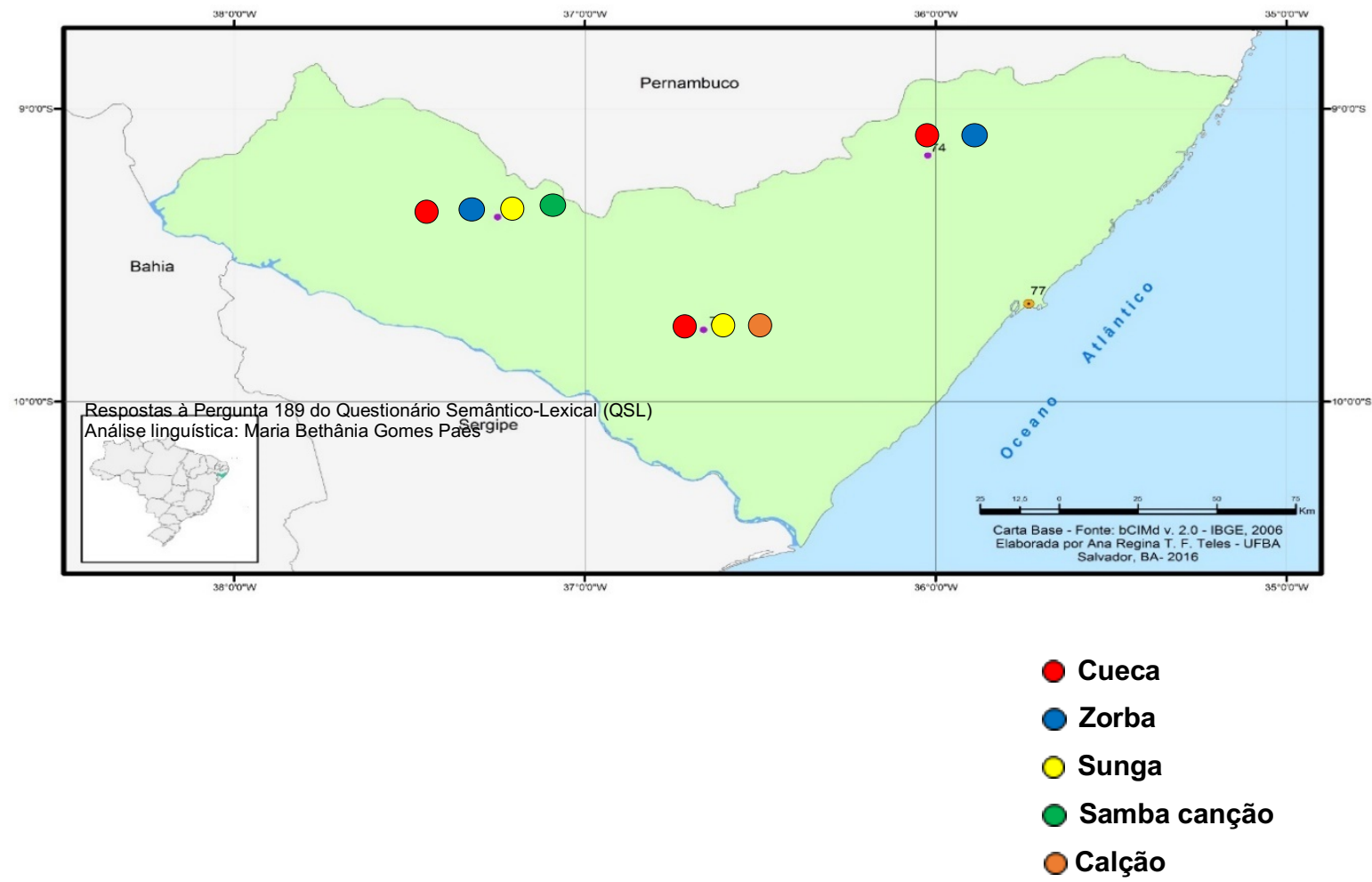

Fonte: Banco de dados do Projeto Atlas Linguístico do Brasil

O Quadro 5 dispõe quantitativamente o uso das variantes pelos informantes dos pontos do ALiB situados no Estado de Sergipe para a pergunta: Qual a roupa que o homem usa debaixo da calça?

Foram registrados os itens lexicais cueca, zorba, sunga, samba canção, calção e ceroula na referida área, como ocorreu em Alagoas.

Quadro 5: Designações para roupa que o homem usa debaixo da calça em Sergipe.
Propriá
Estância

\begin{tabular}{|l|c|c|}
\hline Cueca & 4 ocorrências & 4 ocorrências \\
\hline Zorba & 1 ocorrência & ---- \\
\hline Sunga & 1 ocorrência & 2 ocorrências \\
\hline Samba canção & 1 ocorrência & ---- \\
\hline
\end{tabular}




\begin{tabular}{|l|c|c|}
\hline Calção & ---- & 1 ocorrência \\
\hline Ceroula & ---- & 1 ocorrência \\
\hline
\end{tabular}

Fonte: elaborado pelas autoras.

Os dados demonstram que a variante cueca é a mais recorrente entre os informantes dos pontos do ALiB situados em Sergipe, sendo registrada na fala dos 12 sujeitos considerados no Estado, em resposta à pergunta 189 do QSL, como observado nos dados de Alagoas.

A variante sunga é a segunda lexia mais utilizada em resposta à pergunta 189 do ALiB, sendo observada na fala de 3 dos 12 informantes considerados em Sergipe: em Propriá, na resposta de um informante, e em Santana do Ipanema nos registros de dois informantes. Considerando-se as dimensões diassexual/diageracional, cujos dados foram sistematizados no Quadro 6, o item lexical sunga foi observado em ambos os sexos: em Propriá, apenas no registro de mulher de faixa etária 2; em Estância, sunga foi observado em dados de mulher da faixa etária 1 e em dados do homem de faixa etária 2.

As lexias zorba, samba canção, calção e ceroula foram utilizadas apenas uma vez cada: zorba e samba canção foram observadas na fala de informantes de Propriá, da faixa 2, sendo que a primeira lexia foi utilizada por um homem, e a segunda, por mulher; os itens lexicais calção e ceroula foram utilizados por uma mulher de Estância, pertencente à faixa etária 2.

Segue o Quadro 6 com a distribuição diagenérica/diageracional das variantes para roupa que o homem usa debaixo da calça em Sergipe.

Quadro 6: Distribuição diassexual/ diageracional das variantes para roupa que o homem usa debaixo da calça em

\begin{tabular}{|l|c|c|c|c|}
\hline & Homem- & Homem- & Mulher- & Mulher- \\
& faixa etária 1 & faixa etária 2 & faixa etária 1 & faixa etária 2 \\
\hline Propriá & Cueca & cueca, zorba & Cueca & $\begin{array}{c}\text { sunga, samba } \\
\text { canção, cueca }\end{array}$ \\
\hline Estância & Cueca & cueca, sunga & cueca, sunga & $\begin{array}{c}\text { cueca, ceroula, } \\
\text { calção }\end{array}$ \\
\hline
\end{tabular}

Fonte: elaborado pelas autoras.

$\mathrm{Na}$ Figura 2, a carta linguística formulada com base na distribuição diatópica das lexias referentes às denominações para roupa que o homem usa debaixo da calça em Sergipe. 
Figura 2: Denominações para roupa que o homem usa embaixo da calça em Sergipe

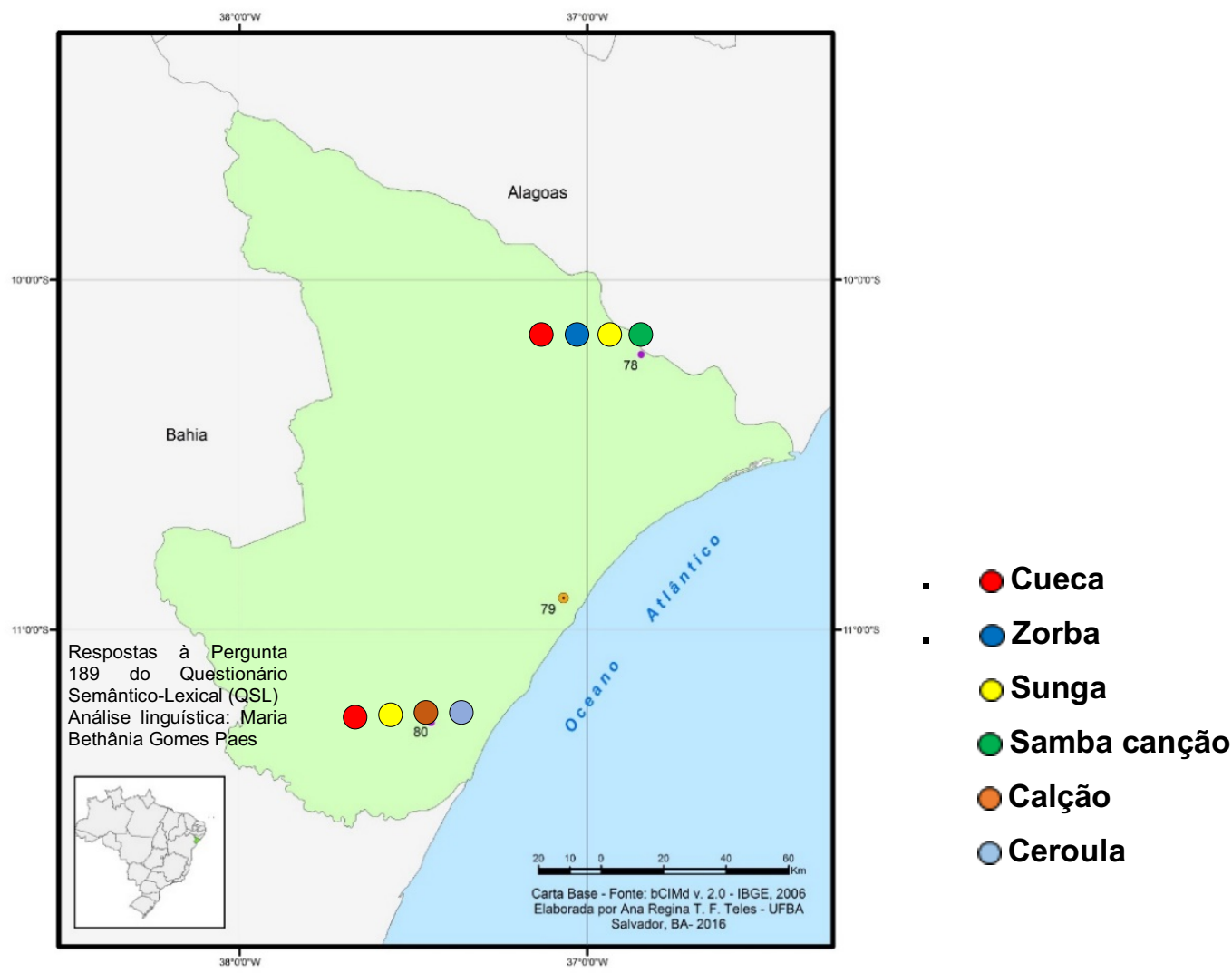

Fonte: Banco de dados do Projeto Atlas Linguístico do Brasil

Análise das designações para roupa que a mulher usa debaixo da saia.

O Quadro 7 apresenta quantitativamente o uso das variantes pelos informantes dos pontos do ALiB situados no Estado de Alagoas para a pergunta: Qual a roupa que a mulher usa debaixo da saia? Foram registrados os itens lexicais calcinha, saiote e biquíni na referida área.

Quadro 7: Designações para roupa que a mulher usa debaixo da saia em Alagoas.

\begin{tabular}{|l|c|c|c|}
\hline & União dos Palmares & Santana do Ipanema & Arapiraca \\
\hline Calcinha & 4 ocorrências & 4 ocorrências & 4 ocorrências \\
\hline Saiote & ---- & 1 ocorrência & ---- \\
\hline Biquini & ---- & ---- & 1 ocorrência \\
\hline
\end{tabular}

Fonte: elaborado pelas autoras.

Os dados demonstram que a variante calcinha é a mais recorrente entre os informantes dos pontos do ALiB situados em Alagoas, sendo observada na fala dos 12 sujeitos considerados no Estado, como resposta à pergunta 189 do QSL. 
As variantes saiote e biquíni foram registradas uma única vez cada, em falantes da faixa etária 2: a primeira foi utilizada por informante mulher, de Santana do Ipanema; a segunda, em dados de homem, de Arapiraca, como pode ser observado no Quadro 8.

Quadro 8: Distribuição diassexual/ diageracional das variantes para roupa que a mulher usa debaixo da saia em

\begin{tabular}{|l|c|c|c|c|}
\hline \multirow{2}{*}{} & Homem- & Homem- & Mulher- & Mulher- \\
& faixa etária 1 & faixa etária 2 & faixa etária 1 & faixa etária 2 \\
\hline União dos Palmares & Calcinha & calcinha & calcinha & Calcinha \\
\hline Santana do Ipanema & Calcinha & calcinha & calcinha & $\begin{array}{c}\text { calcinha, } \\
\text { saiote }\end{array}$ \\
\hline Arapiraca & calcinha, biquíni & calcinha & calcinha & Calcinha \\
\hline
\end{tabular}

Fonte: elaborado pelas autoras.

Na Figura 3, apresenta-se a carta linguística formulada com base na distribuição diatópica das lexias referentes às denominações para roupa que a mulher usa debaixo da saia em Alagoas.

Figura 3: Denominações para roupa que a mulher usa debaixo da saia em Alagoas

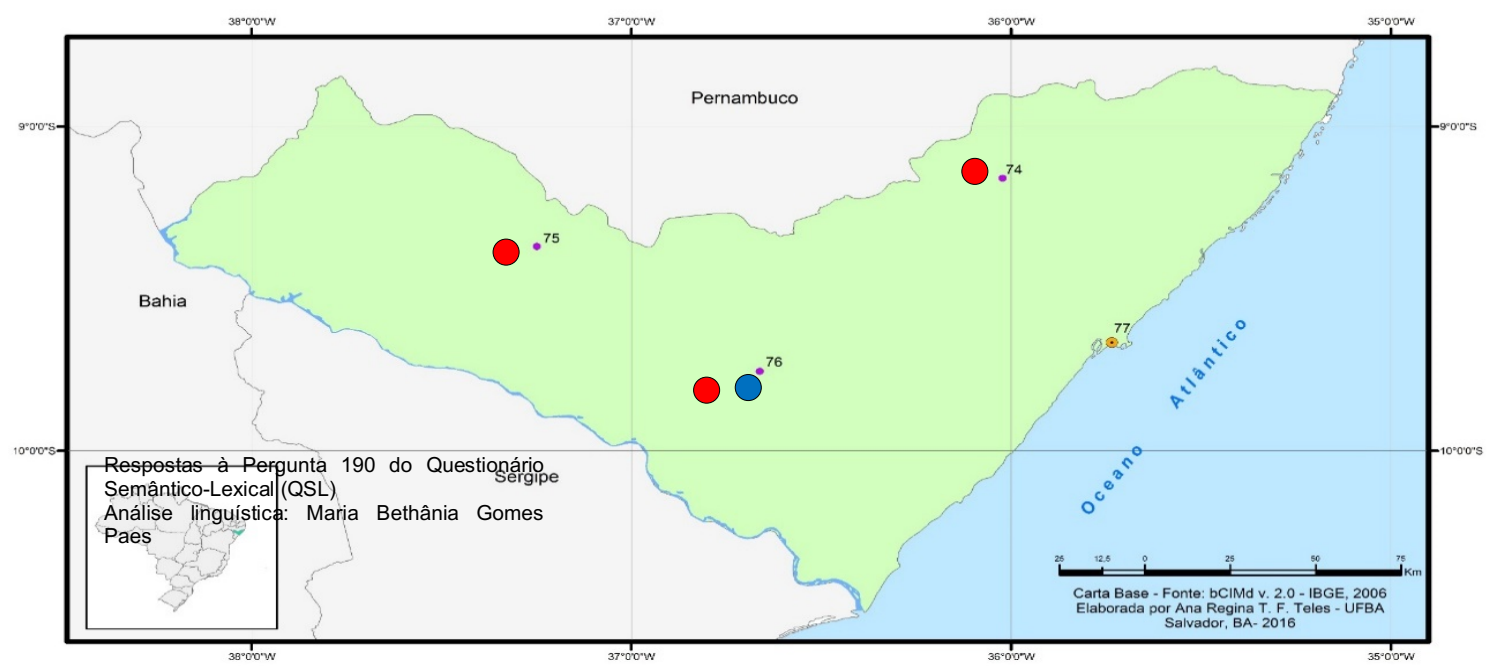


O Quadro 9 apresenta as variantes utilizadas pelos informantes dos pontos do ALiB situados no Estado de Sergipe para a pergunta: Qual a roupa que a mulher usa debaixo da saia em Sergipe? Foram registrados os itens lexicais calcinha, tanga, fio dental e calçola/calçolão na referida área.

Quadro 9: Designações para roupa que a mulher usa debaixo da saia em Sergipe.

\begin{tabular}{|l|c|c|}
\hline & Propriá & Estância \\
\hline Calcinha & 4 ocorrências & 4 ocorrências \\
\hline Saiote & ---- & \\
\hline Biquíni & ---- & ---- \\
\hline Tanga & 1 ocorrência & 1 ocorrência \\
\hline Fio dental & 1 ocorrência & ---- \\
\hline Calçola/calçolão & 1 ocorrência & 1 ocorrência \\
\hline
\end{tabular}

Fonte: elaborado pelas autoras.

Os dados demonstram que a variante calcinha é a mais recorrente entre os informantes dos pontos do ALiB situados em Sergipe, sendo observada, como resposta à pergunta 189 do QSL, na fala dos 12 sujeitos considerados no Estado.

As variantes tanga e calçola/calçolão foram utilizadas duas vezes cada, sempre na faixa etária 2: a primeira foi utilizada por informante homem, de Estância, e por mulher, de Propriá; a segunda é utilizada pelas mulheres das duas faixas etárias consideradas.

A variante fio dental foi registrada uma única vez na fala da informante mulher, faixa etária 2, de Propriá, como observado no Quadro 10.

Quadro 10: Distribuição diassexual/diageracional das variantes para roupa que a mulher usa debaixo da saia em Sergipe.

\begin{tabular}{|l|c|c|c|c|}
\hline \multirow{2}{*}{} & \multicolumn{2}{|c|}{ Homem } & \multicolumn{2}{c|}{ Mulher } \\
\cline { 2 - 5 } & faixa etária 1 & faixa etária 2 & faixa etária 1 & faixa etária 2 \\
\hline Propriá & Calcinha & calcinha & calcinha & $\begin{array}{c}\text { calcinha, tanga, } \\
\text { fio dental, calçola }\end{array}$ \\
\hline Estância & Calcinha & calcinha, tanga & calcinha, calçolão & Calcinha \\
\hline
\end{tabular}

Fonte: elaborado pelas autoras.

A seguir, a carta linguística formulada com base na distribuição diatópica das lexias referentes às denominações para roupa que a mulher usa debaixo da saia em Sergipe.

Figura 4: Denominações para roupa que a mulher usa debaixo da saia em Sergipe 


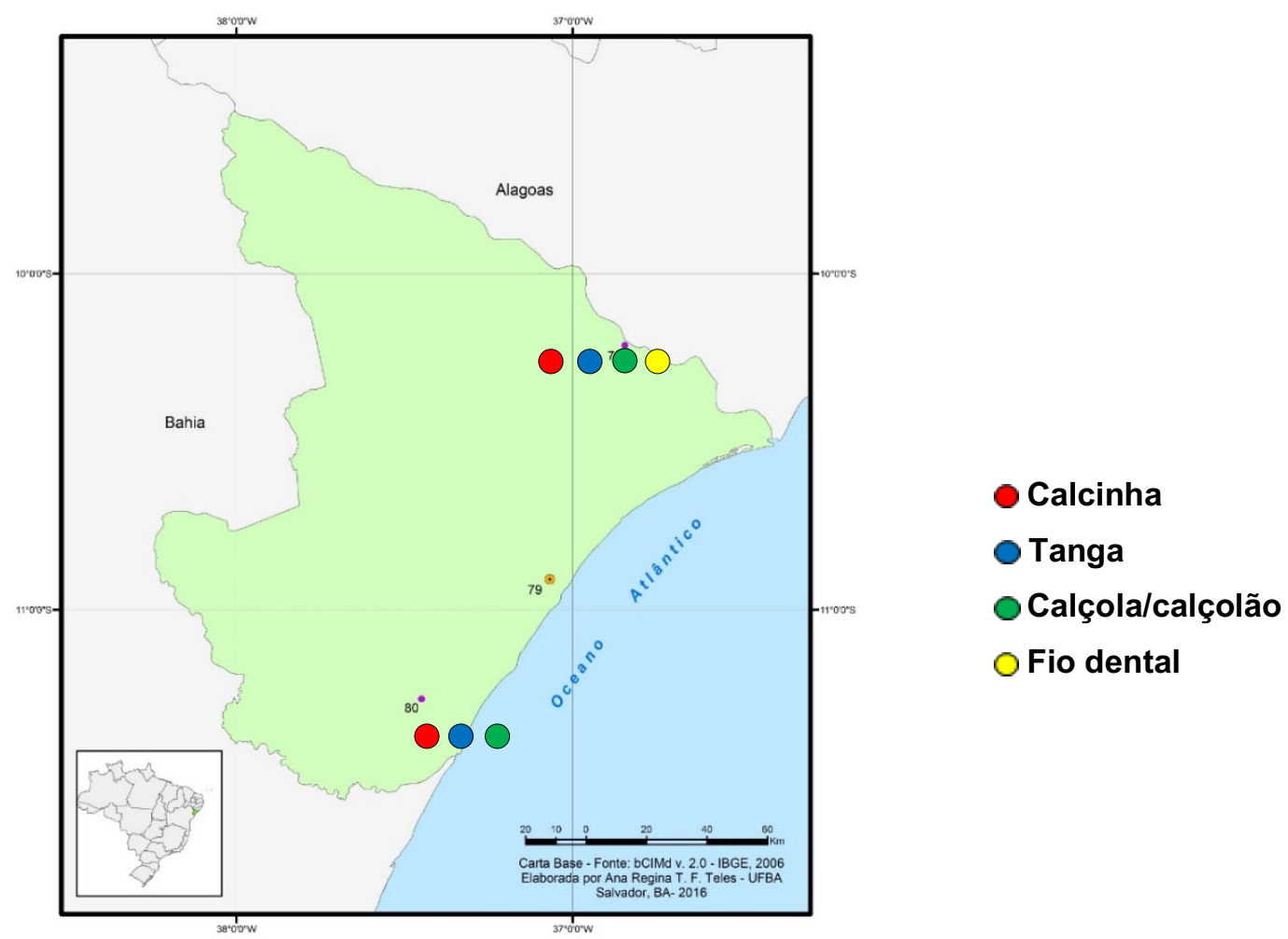

Fonte: Banco de dados do Projeto Atlas Linguístico do Brasil

As relações temporais feitas pelo falante quanto ao uso das lexias

Nos inquéritos analisados foram observadas também relações feitas por alguns informantes quanto ao fator tempo como condicionador do uso de determinadas lexias no presente ou passado. Tais relações foram observadas na fala dos dois informantes do sexo feminino, da faixa etária II, cada um deles residentes em Propriá- SE e Estância- SE, ao serem questionados sobre qual roupa que o homem usa debaixo da calça, como disposto a seguir:

(1) "Sunga. Antigamente era samba canção, né, ou cueca." [...] Não, porque a cueca de antigamente ela era aberta aqui, né, é, muita gente usa ainda, né, ela é aberta aqui, tem os dois [...] que prende [...] A sunga é a fechada como calcinha, né." (mulher, faixa etária II, ensino fundamental, Propriá- SE);

(2) "Bom, na, na minha juventude chamava era ceroula, [..] calção [...] mas, de um tempo pra cá aí é cueca [...]." (mulher, faixa etária II, ensino fundamental, Estância- SE)

Na fala da informante de Propriá, é possível inferir que (i) o item lexical sunga é marcado como designação mais moderna; (ii) a lexia samba canção é marcada como designação mais antiga; (iii) cueca é a variante mais utilizada no passado e no presente, havendo alteração nos modelos de ontem e hoje. 
Considerando-se a fala da informante de Estância, observa-se que o item lexical cueca é marcado como designação mais moderna, sendo as lexias ceroula e calção marcadas como designações mais antigas para a roupa que o homem usa debaixo da calça.

\section{Considerações Finais}

A partir da coleta e da análise dos dados, pode-se concluir que as variantes cueca e calcinha foram as mais produtivas nos pontos observados como resposta às perguntas 189 e 190 do QSL, figurando na fala dos 20 informantes considerados neste estudo. A dimensão diatópica, porém, não se demonstra como relevantes na determinação das lexias pelo falante.

Além de cueca e calcinha, outras variantes são apontadas pelos falantes como alternativa às supracitadas. A variante zorba, a única não dicionarizada entre as registradas nas falas dos informantes, foi observada em quatro inquéritos, número acima de termos como samba canção (1 registro), e próxima em quantidade da variante sunga (5 registros), apesar de ambas serem nomeações de uma peça do vestuário masculino vestida por baixo da calça. $O$ uso de zorba remete à figura de linguagem metonímia, uma vez que é utilizada uma marca comercial para nomear o produto que ela comercializa, podendo tal fato ser interpretado como o uso do recurso da expressividade pelo falante para potencializar sua capacidade comunicativa.

Os dados também demonstram que os homens de faixa etária 1 são os que menos indicam variantes alternativas à cueca e calcinha, podendo este fato ser indicador de que as demais variantes são inovadoras, com as variantes mais produtivas sendo consideravelmente prevalente na fala dos informantes do território em questão.

A análise de possíveis relações diassexuais observadas entre o uso de determinada lexia e a forma como o falante a situa temporalmente no discurso é extremamente relevante em estudos futuros, na medida em que pode demonstrar o comportamento linguístico dos falantes ao longo do tempo em determinadas comunidades linguísticas associado a diferentes fatores sociais.

\section{Referências}

BASÍLIO, M. Formação e classes de palavras no português do Brasil.3. ed., 3a impressão. São Paulo: Contexto, 2017.

CARDOSO, Suzana Alice Marcelino da Silva. Geolinguística: tradição e modernidade. São Paulo: Parábola, 2010. COMITÊ NACIONAL DO PROJETO ALiB (Brasil). Atlas Linguístico do Brasil: questionário 2001. Londrina: Ed. UEL, 2001.

CHAMBERS, J. K.; TRUDGILL, P. La Dialetología. Trad. de Carmen Morán Gonzalez. Madrid: Visor Libros, 1994. FERREIRA, A. B. de H. Novo Dicionário Aurélio da língua portuguesa. Curitiba: Positivo, 2009.

HOUAISS, A. Dicionário Houaiss de língua portuguesa. São Paulo: Objetiva, 2001.

LABOV, William. Padrões Sociolinguísticos. Trad. Marcos Bagno, Maria Marta Pereira Scherre, Caroline Rodrigues Cardoso. São Paulo: Parábola, 2008.

NASCENTES, A. O linguajar carioca. Rio de Janeiro: Organização Simões, 1953.

OLIVEIRA, Ana Maria Pinto Pires de; ISQUERDO, Aparecida Negri (orgs.). A ciência do léxico: lexicologia, lexicografia, terminologia. Campo Grande: Ed. UFMS, 1998. 
PAIM, Marcela Moura Torres. A variação lexical do português falado no Brasil: reflexões sobre o campo semântico vestuário e acessórios nos dados do Projeto ALiB. In: VI SIGET - Simpósio Internacional de Gêneros Textuais, Natal. Anais do VI SIGET. Natal: UFRN, 2011. Acesso em: 19 mai 2017.

O Sutiã na Bahia: Um Estudo em Dois Tempos Diferentes. SIGNUM: Estud. Ling.,

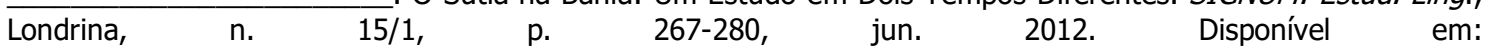
http://www.uel.br/revistas/uel/index.php/signum/article/view/11353. Acesso em: 19 mai 2017.

RIBEIRO, Silvana Soares Costa. Jogos e diversões infantis: preferências linguísticas e variáveis sociais. In: RIBEIRO, Silvana Soares Costa; COSTA, Sônia Bastos Borba; CARDOSO, Suzana Alice Marcelino da Silva (orgs). Dons sons às palavras- nas trilhas da língua portuguesa. Salvador: EDUFBA, 2009. p. 237-261. 